\title{
Effect of TiN Inclusion on Fracture Toughness in Ultrahigh Strength Steel
}

\author{
Jing-Yuan LI') and Wei-Yi ZHANG ${ }^{2)}$ \\ 1) Department of Metal Material, Cheng-Du University of Science \& Technology, Cheng-Due, Sichunan Province, China. \\ College of Rail-way, Liao-Ning Prov., China.
}

2) Dalian

(Received on December 21, 1987: accepted in the final form on September 9, 1988)

\begin{abstract}
The investigation was conducted on 6 specimens of an identical composition except for $\mathrm{N}$ and Ti contents, the specimens were remarkably free of nonmetallic inclusions other than TiN inclusion.

The quasi-dynamic method has been used to investigate the condition of nucleation, growth and propagation of microcrack from TiN inclusion.

In summarizing the present study the following conclusion can be made:

(1) Fracture toughness $K_{\mathrm{IC}}$ is decreased rapidly with increasing volume fraction of inclusion $\left(f_{v}\right)$ for $f_{v}<0.1 \%$ and becomes insensitive when $f_{v}>0.1 \%$ where the percentage of cracked-TiN reaches a limiting value.

(2) The percentage of cracked-TiN is determined by the true fracture strain $\varepsilon_{f}$ and its propagation depends mainly on the critical true fracture strain $\varepsilon_{;}$. The $\varepsilon_{;}$can be computed by using both McClintock's model and Wall-Hill method as follows:

$$
\varepsilon_{f}^{*}=0.0345 \ln \left(\bar{d}_{t} / \bar{a}\right)
$$
\end{abstract}

Thus the $\varepsilon_{f}^{*}$ can be correlated with the inclusion spacing $\left(\bar{d}_{t}\right)$ and size $(\bar{a})$.

(3) Based on the testing results, we get a similar relation to the ductile fracture model proposed by Rice, that is:

$$
K_{\mathrm{IC}}=\left(E \cdot \sigma_{y} \cdot \bar{d}_{t}\right)^{1 / 2}
$$

KEY WORDS: fracture toughness; inclusion; ultrahigh strength steel; titanium nitride; quasi-dynamic method.

\section{Introduction}

The toughness of ultrahigh strength steels is an important property for their use as structural materials. Some catastrophic accidents have been caused by fracture under lower stress. It is confirmed from fracture mechanics that the crack size in the structural material is larger than the critical size. Cracks can cause a high concentration of stress in the localized region at their tips and the likelihood of complete fracture of the material depends on their propagation. Brooksbank and Andrews ${ }^{1)}$ have shown that stress concentrations around inclusions in steel may be formed duc to a difference in thermal compression between the inclusion phases and the steel matrix. Birkle et $a .^{2-9)}$ have given the mechanism of microcrack uncleation. McClintock ${ }^{10}$ and Rice ${ }^{11)}$ have also proposed the models for microcrack growth. Thomson and Hancook ${ }^{12)}$ have been summarized and made the scientific researches on the ductile failure by void nucleation, growth and coalescence. Since inclusions play an important role in ductile failure, it is important to determine the metallurgical and physical parameters which control microcracks nucleation. The main purpose of this paper is to investigate both the condition of microcrack nucleation, growth and propagation from inclusions and the relationship between inclusions and fracture toughness in an ultrahigh strength steels.

\section{Experiments}

The investigation was conducted on 6 steels with similar compositions except for $\mathrm{Ti}$ and $\mathrm{N}$ contents. The specimens were remarkably free of nonmetallic inclusions other than TiN inclusion. Their compositions are shown in Table 1.

The tensile tests was carried out on standard round tensile specimens using a ZDM-30T machine loaded by hydrostatic press. The evaluation of the fracture

\begin{tabular}{|c|c|c|c|c|c|c|c|c|c|c|c|}
\hline \multirow{2}{*}{ No. } & \multicolumn{11}{|c|}{ Composition } \\
\hline & G & $\mathrm{Si}$ & $\mathrm{Mn}$ & $\mathrm{Ni}$ & Mo & $\mathrm{Cr}$ & $\mathbf{S}$ & $\mathbf{P}$ & (O) & $\mathrm{Ti}$ & $\mathrm{N}$ \\
\hline 1 & 0.43 & 0.24 & 0.57 & 0.69 & 0.97 & 0.97 & 0.016 & 0.005 & 0.0009 & 0.07 & 0.0043 \\
\hline 2 & 0.45 & 0.23 & 0.65 & 0.70 & 0.99 & 1.00 & 0.015 & 0.005 & 0.0012 & 0.11 & 0.0091 \\
\hline 3 & 0.40 & 0.23 & 0.73 & 0.65 & 0.92 & 0.98 & 0.016 & 0.005 & 0.0009 & 0.19 & 0.0120 \\
\hline 4 & 0.42 & 0.26 & 0.45 & 0.82 & 1.07 & 1.06 & 0.013 & 0.005 & 0.0027 & 0.17 & 0.0094 \\
\hline 5 & 0.45 & 0.27 & 0.76 & 0.82 & 1.04 & 1.08 & 0.013 & 0.005 & 0.0026 & 0.19 & 0.0170 \\
\hline 6 & 0.48 & 0.26 & 0.48 & 0.86 & 1.06 & 1.06 & 0.012 & 0.005 & 0.0016 & 0.26 & 0.0377 \\
\hline
\end{tabular}

Table 1. Composition of specimens. (wt\%) 
toughness $K_{\mathrm{IC}}$ was made on single-edge notched (SEN) three point bending specimens of $15 \times 30 \times 140$ $\mathrm{mm}$ in dimensions cut with the long axis along the rolling direction.

The heat treatment of specimens consisted of normalizing at $1173 \mathrm{~K}$ is salt bath, re-austenitizing for $30 \mathrm{~min}$ at $1153 \mathrm{~K}$ followed by quenching in oil, and tempering for $2 \mathrm{~h}$ at $783 \mathrm{~K}$ followed by cooling in air. The tempering treatment was intented to provide a similar microstructure.

The quasi-dynamic process of nucleation and propagation of microcrack from inclusions was observed in plane tensile specimens. The dimension of plane tensile spccimen is shown in Fig. 1.

At first, the central part of a plane-specimen was polished; the strain was measured and the number of cracked inclusions was counted by a metallographic microscope.

\section{Results}

The specimens had the similar microstructure of Sorbite (Fig. 2) and grain size was Grade No. 11 based on ASTM Standard (Fig. 3).

Content, number, size and spacing of inclusions were determined by AIA Quantimet-720. The frequency distribution of nitride inclusions size and area percent are shown in Figs. 4 and 5, respectively.

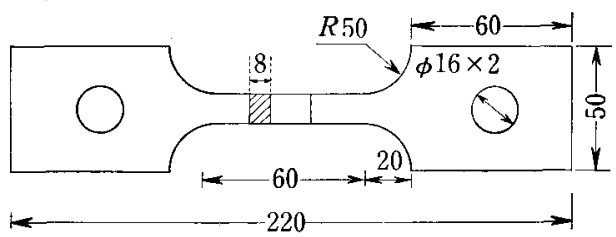

Fig. 1. Dimension of plane specimen.
The spacing between the inclusions on a planar section is given in Table 2 , and volume fraction is listed in the same table. The average spacing $\left(\bar{d}_{t}\right)$ is calculated by the formular

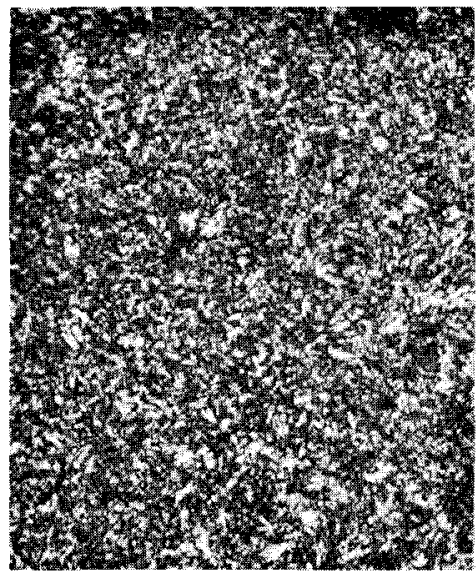

Fig. 2. Microstructure showing Sorbite. $(\times 500)(\times 3 / 4)$

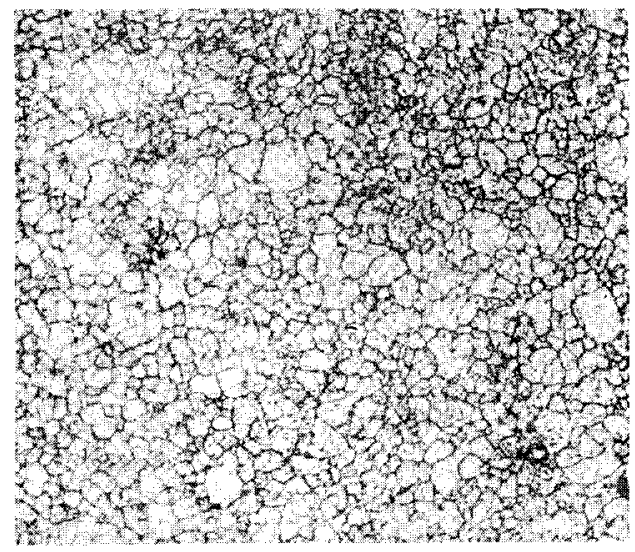

Fig. 3. Microstructure showing grain size. $(\times 400)(\times 3 / 4)$

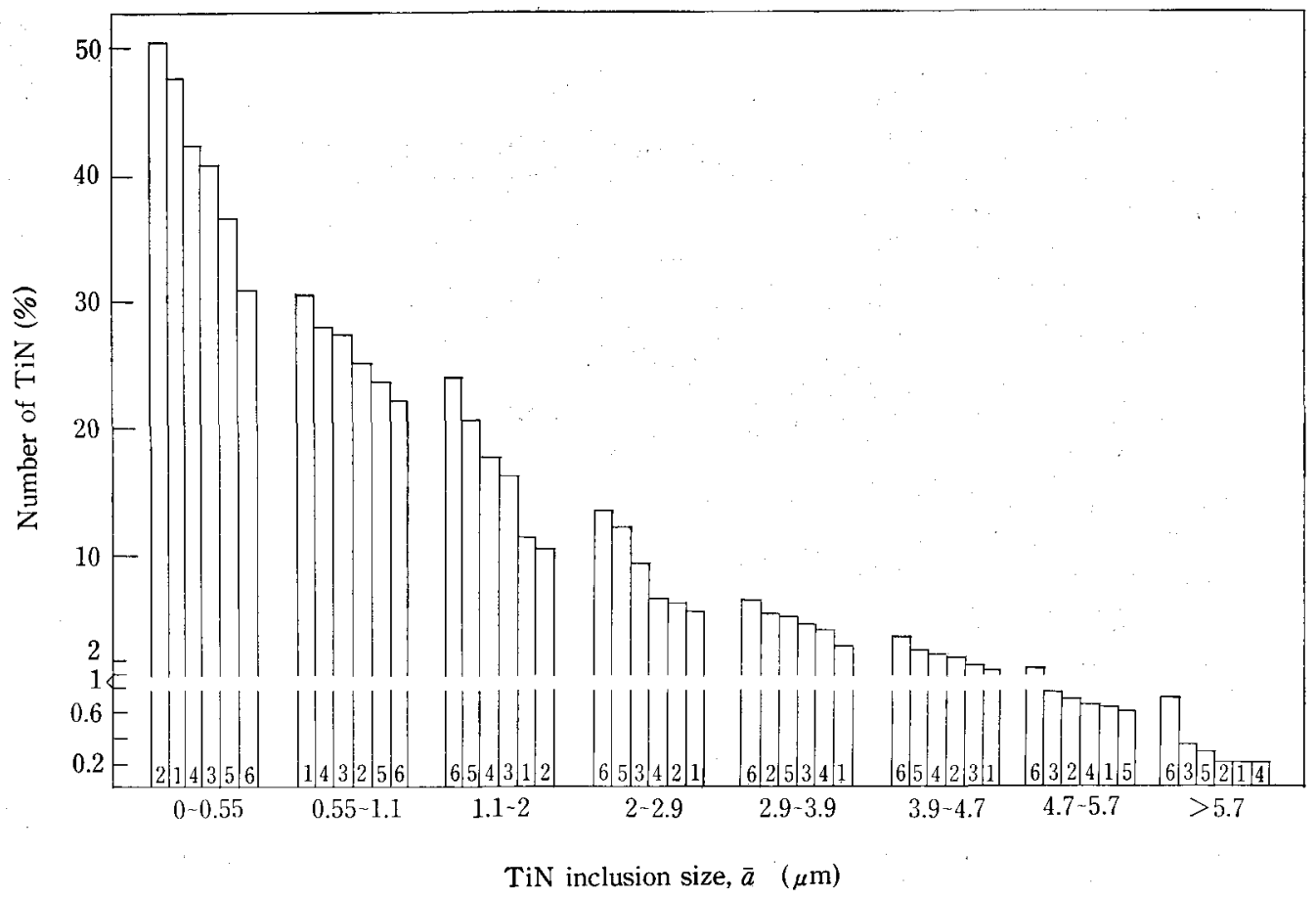

Fig. 4. Size distribution of TiN inclusion. (Numbers in the figure show specimen number.) 


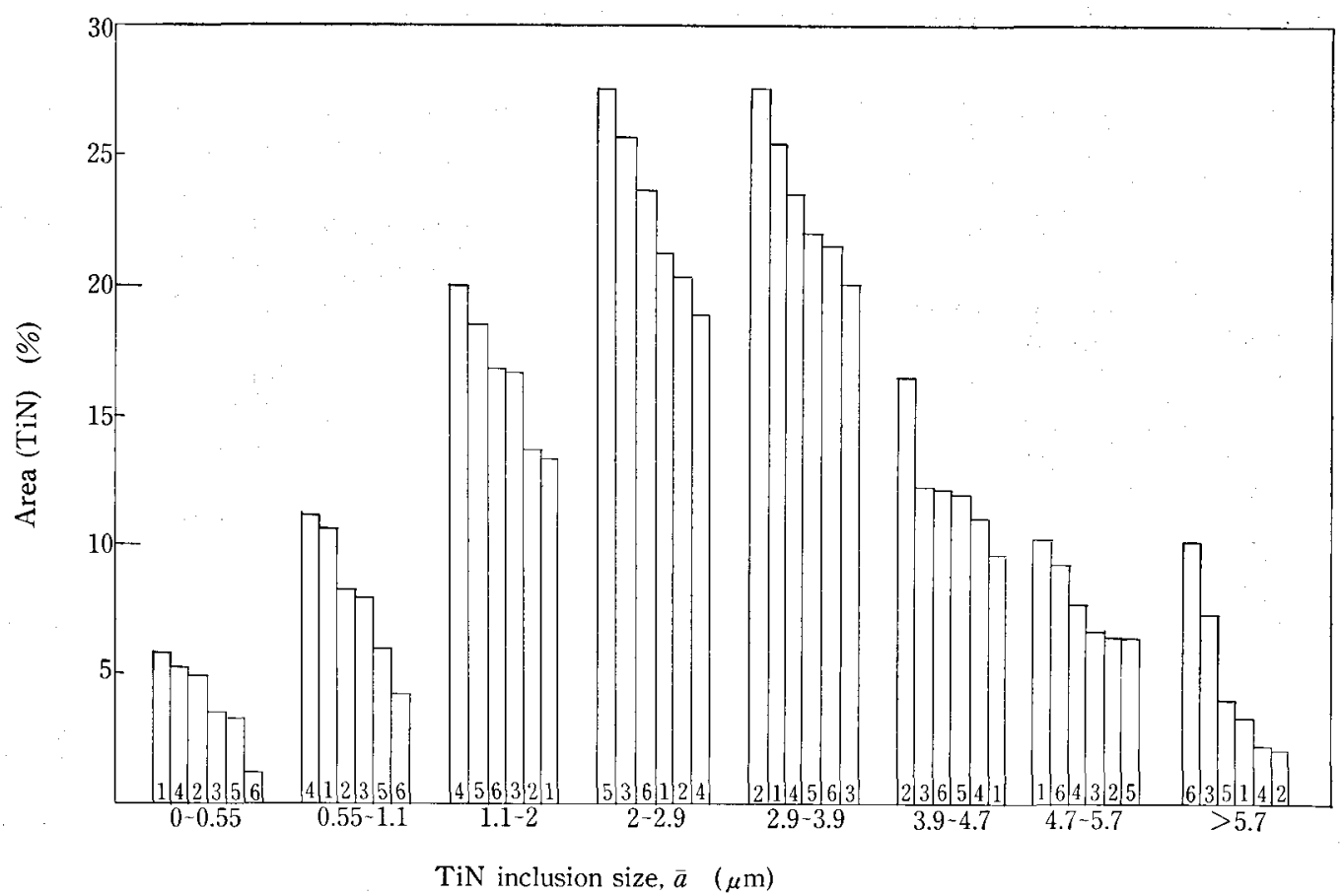

Fig. 5. Size and area percent of TiN inclusions. (Numbers in the figure show specimen number.)

Table 2. Quantitative data on TiN inclusion.

\begin{tabular}{lcccccc}
\hline $\begin{array}{l}\text { Specimen } \\
\text { No. }\end{array}$ & 1 & 2 & 3 & 4 & 5 & 6 \\
\hline $\begin{array}{l}\text { Vol. frac- } \\
\text { tion, } f_{v} \\
(\%)\end{array}$ & 0.062 & 0.049 & 0.071 & 0.089 & 0.103 & 0.149 \\
$\begin{array}{l}\text { Spacing, } \\
d_{t}(\mu \mathrm{m})\end{array}$ & 87.42 & 74.79 & 64.7 & 55.77 & 53.16 & 50.86 \\
$\begin{array}{l}\text { Average } \\
\text { TiN size } \\
(\mu \mathrm{m})\end{array}$ & 1.77 & 1.78 & 2.09 & 1.99 & 2.00 & 2.25 \\
\hline
\end{tabular}

Table 3. Tensile properties and fracture toughness.*

\begin{tabular}{cccccccc}
\hline No. & $\begin{array}{c}\sigma_{y} \\
(\mathrm{MPa})\end{array}$ & $\begin{array}{c}\sigma_{b} \\
(\mathrm{MPa})\end{array}$ & $\begin{array}{c}\sigma_{f} \\
(\mathrm{MPa})\end{array}$ & $\begin{array}{c}\delta_{5} \\
(\%)\end{array}$ & $\begin{array}{c}\Psi \\
(\%)\end{array}$ & $\begin{array}{c}\varepsilon_{f} \\
(\%)\end{array}$ & $\begin{array}{c}K_{\mathrm{IC}} \\
(\mathrm{MPa} \sqrt{\mathrm{m}})\end{array}$ \\
\hline 1 & 1448 & 1488 & 2292 & 12.7 & 53.1 & 75.8 & 90.9 \\
2 & 1431 & 1507 & 2332 & 11.9 & 53.0 & 75.6 & 87.3 \\
3 & 1395 & 1428 & 2343 & 13.3 & 50.2 & 69.9 & 84.9 \\
4 & 1461 & 1521 & 2300 & 11.8 & 51.6 & 72.6 & 82.7 \\
5 & 1439 & 1529 & 2130 & 10.3 & 48.5 & 66.6 & 81.1 \\
6 & 1444 & 1541 & 2253 & 11.3 & 47.0 & 63.5 & 80.4 \\
\hline
\end{tabular}

* Each data is the average value of 3 specimens.

$$
\bar{d}_{t}=\left(\frac{A}{\mathcal{N}}\right)^{1 / 2}
$$

where, $A$ : the total measured area

$\mathcal{N}:$ the total number of inclusion.

The $K_{\text {IC }}$ values which validity was judged by the thickness of specimens $\mathrm{B} \geqslant 2.5\left(K_{Q} / \sigma_{y s}\right)^{2}$ and smooth tensile properties are given in Table 3.

The observation of the quasi-dynamic process of nucleation and propagation of a microcrack in a TiNinclusion is shown in Fig. 6 for a plane tensile specimen.

The type and the chemical composition of the inclusions were analyzed by $\mathrm{X}$-ray diffraction and software based X-ray microanalysis system, respectively.

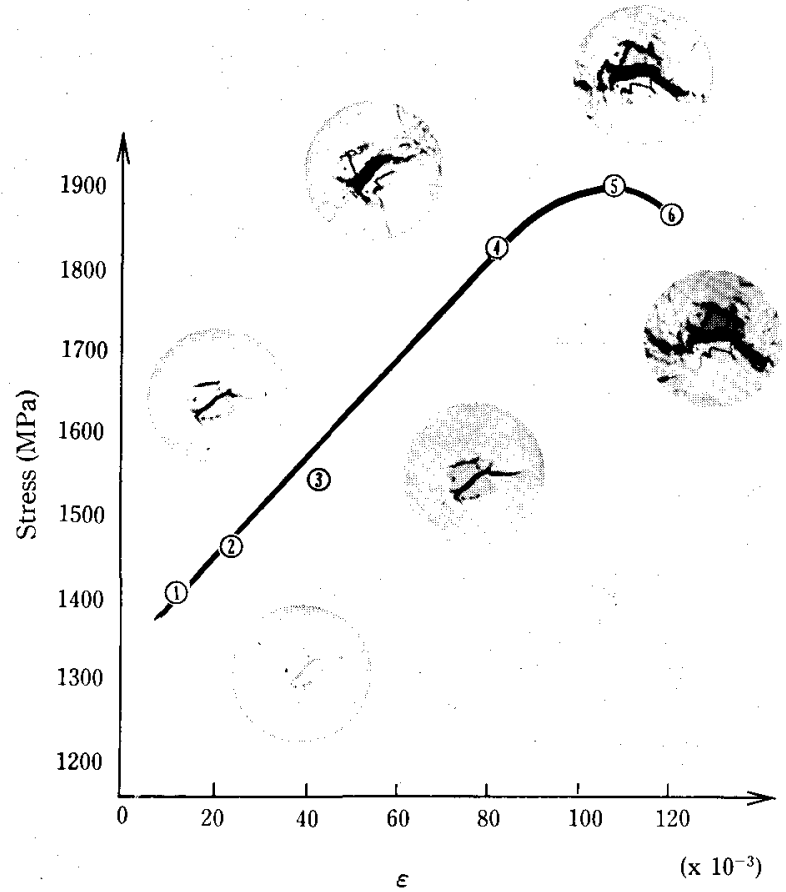

Fig. 6. Microcrack nucleation in a TiN inclusion as a function of strain and stress during tensile testing.

The results obtained showed that the structure of inclusion was the same as that of TiN.

The elastic modulus and Poisson's ratio were determined by the use of 3 specimens. The values are given in Table 4.

\section{Discussion}

\subsection{Effect of the Volume Fraction of TiN-inclusions on Fracture Toughness}

The area fraction of inclusions which is equivalent 
to the volume fraction $f_{v}$ is listed in Table 2. The relation between $K_{\mathrm{IC}}$ and $f_{v}$ shows in Fig. 7. There was a linear relationship between $f_{v}$ and $K_{\mathrm{Ic}}$ when $f_{v}<0.1 \%$. However, $K_{\text {IC }}$ decreases slowly with increasing $f_{v}$ in the range over $0.1 \%$. This behavior was related to the percentage of the number of cracked TiN. It increased with increasing strain before necking point, but the percentage of microcracked-TiN was kept as nearly constant level after necking point (Figs. 8 and 9), i.e., the number of microcracked TiN had a limiting value. Alternatively, the number of microcracked TiN inclusion was propotional to the volume fraction $\left(f_{v}\right)$ of TiN inclusion, and was controlled by strain. Thercfore, $K_{\mathrm{IC}}$ values were found to decrease rapidly as $f_{v}$ increased up to $0.1 \%$ and become insensitive when $f_{v}>0.1 \%$ where the percentage of microcracked TiN reached a limiting value.

\subsection{Inclusion Size vs. Microcracked Nucleation}

From the observation of plane tensile specimens the true fracture strains for different size TiN-inclusions were different. The larger size inclusion cracked initially at a strain less than $1 \%$, but TiN below 0.5 $\mu \mathrm{m}$ in size did not crack until necking occurred. Inclusion size (a) was related to true fracture strain as given in Table 5 .

The calculated strain, $\varepsilon_{0} \%$ in Table 5 , is based on Tanaka's model (Energy Criterion) ${ }^{9)}$ relating to the void formation condition on spherical inclusion interface. In comparison with the two strain values $\left(\varepsilon_{f}\right.$ and $\varepsilon_{c}$ ) in Table 5, it is revealed that the both values are in good agreement. For example, the $\varepsilon_{f} \%$ and $\varepsilon_{c} \%$ were $0.657 \%$ and $0.68 \%$, respectively when TiN size was $13.2 \mu \mathrm{m}$. Therefore, the true fracture strain $\left(\varepsilon_{f}\right)$ measured by strain gauge is in correspondence

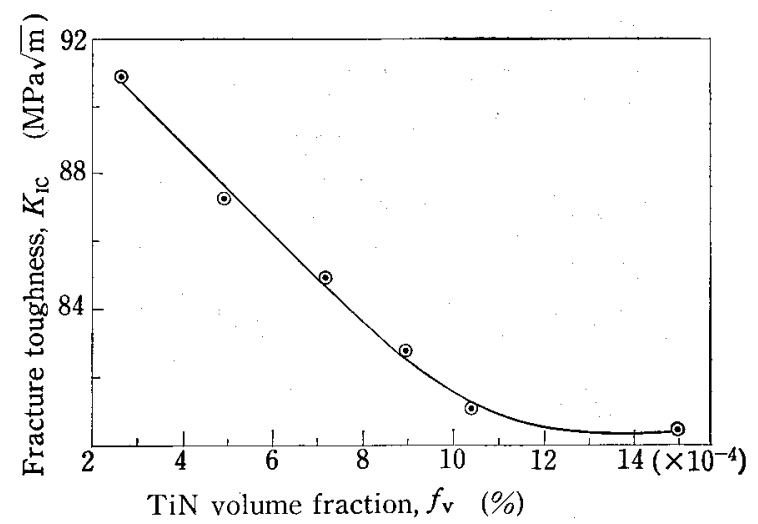

Fig. 7. Effect of TiN volume fraction on fracture toughness.

Table 4. Young's modulus $E$, shear modulus $G$, and Poisson's ratio $\nu$ of specimens.*

\begin{tabular}{lcccc}
\hline No. & 4 & 5 & 6 & Average \\
\hline$E(\mathrm{GPa})$ & 213 & 212 & 211 & 212 \\
$G(\mathrm{GPa})$ & $\mathbf{8 0 . 9}$ & 80.4 & 81.3 & 80.8 \\
$\nu$ & 0.32 & 0.32 & 0.30 & 0.31 \\
\hline
\end{tabular}

* Each datum is the average value of two specimens.

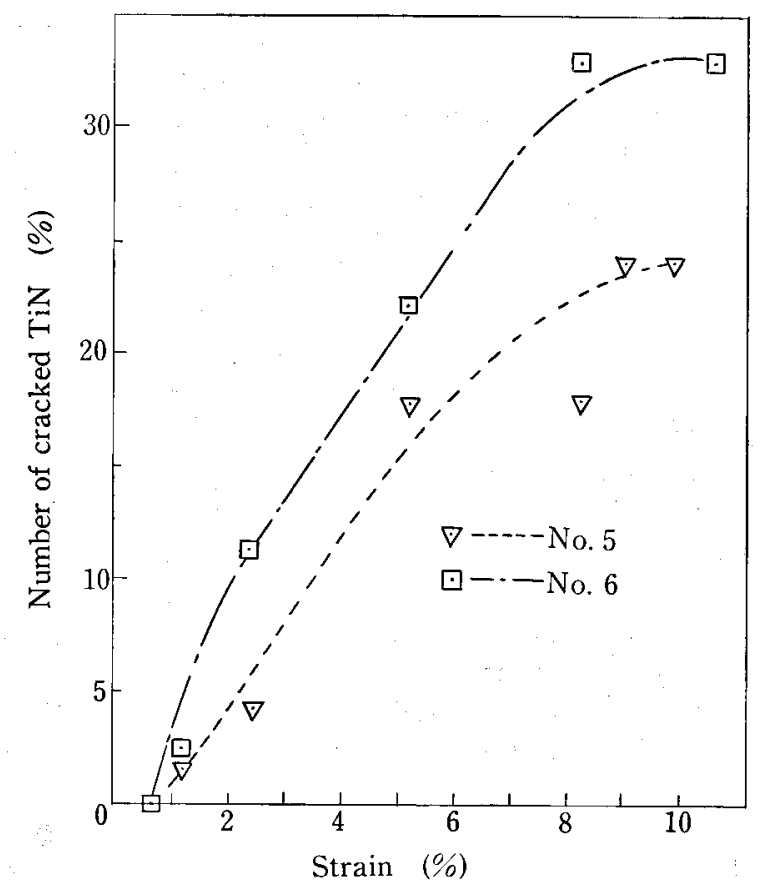

Fig. 8. Relation between percentage of cracked TiN and strain. (before necking point)

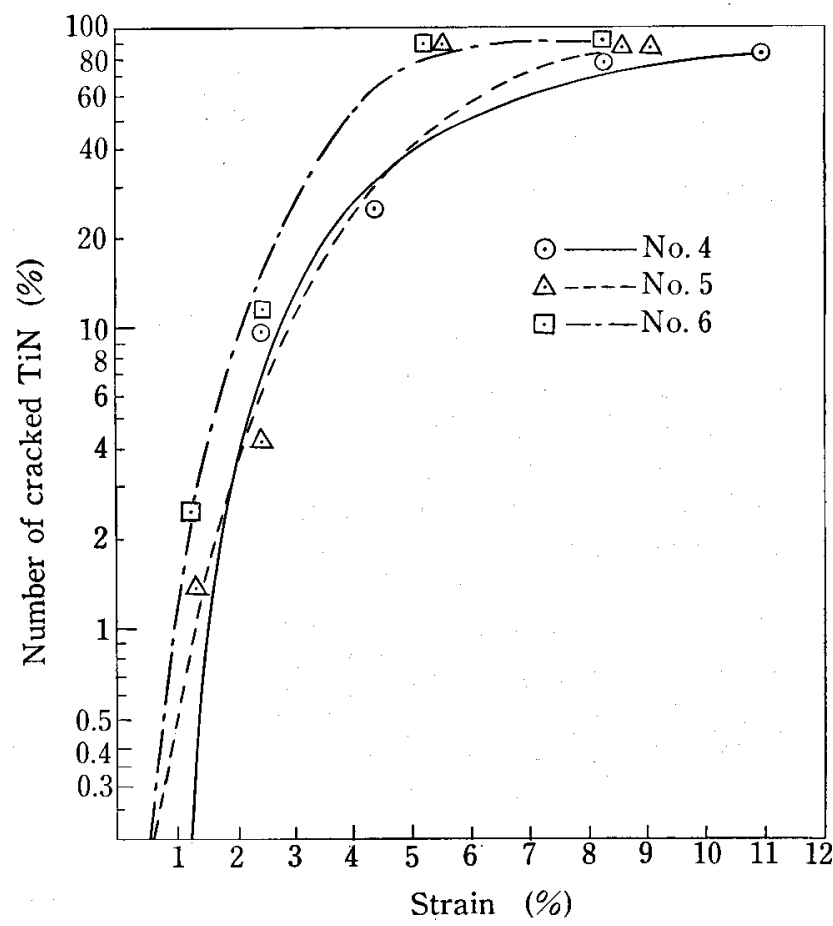

Fig. 9. Relation between percentage of cracked TiN and strain. (after necking point)

Table 5. TiN size and true fracture strain $\left(\varepsilon_{f}\right)$

$\begin{array}{lccll}\text { TiN size, } a(\mu \mathrm{m}) & 13.2 & 5.8 & 1.6 & 1.0 \\ \text { Fracture strain, } \varepsilon_{f}(\%) & 0.68 & 1.2 & 2.4 & 4.32 \\ \text { Calculated strain, }{ }^{* *} \varepsilon_{c}(\%) & 0.657 & 1.0 & 1.89 & 2.39\end{array}$

* The values are measured by strain gauge.

** The material constants was used for calculating $\varepsilon_{c}$ : $E(\mathrm{TiN}) 317 \mathrm{GPa}, \quad E$ (Matrix) $212 \mathrm{GPa}$, $\nu$ (TiN) $0.19, \quad \nu$ (Matrix) 0.31 . 
with critical strain of microcrack nucleation $\left(\varepsilon_{c}\right)$, so that the TiN-size $(a)$ is in correspondence with critical size $a_{e}$, and $a_{c}$ varies inversely with $\varepsilon_{c}$. It is possible to extent Tanaka's model from spherical to non-spherical inclusion interface.

\subsection{Inclusion Spacing and Size vs. Critical True Fracture Strain}

The microcrack nucleation in TiN inclusion is controlled by critical strain $\varepsilon_{c}$. The crack propagation occurs through the microcrack coalescence, and growth. When all the TiN inclusions in an aggregative area are torn off, the crack will be propagated. However, the tear of aggregative area may be controlled by true fracture strain $\varepsilon_{f}^{*}$. Since $\varepsilon_{f}^{*}$ is a micro-parameter, it can not be determined from the mechanical testing on a macroscale. The $\varepsilon_{f}^{*}$ was assumed to $\varepsilon_{f} / 3$ by Hahn-Rosenfield, ${ }^{13)} 2 \varepsilon_{f} / 3$ by Osborne-Embury ${ }^{14)}$ and $\varepsilon_{f}$ by the others, where $\varepsilon_{f}$ represents the true fracture strain under the uni-axial tension.

The critical true fracture $\varepsilon_{f}^{*}$ can be computed using McGlintock's void coalescence model for elliptical cavities, i.e.,

$$
\varepsilon_{f}^{*}=\frac{(1-n) \ln l_{0} / 2 r}{\sin h\left[(1-n) \times\left(\sigma_{11}+\sigma_{22}\right) / \frac{2 \bar{\sigma}}{\sqrt{3}}\right]}
$$

where, $l_{0}$ : the initial void spacing

$r_{0}$ : the initial micro semi-axis of the preexisting voids

$\bar{\sigma}: \quad$ the effective stress

$\sigma_{11}, \sigma_{22}$ : the stress parallel to the major and minor axes of the elliptical void, respectively.

We take the TiN cracked as a void and let the length of TiN as a void diameter, i.e., $\bar{a}=2 r_{0}$, and the inclusion spacing $d_{t}$ as the initial void spacing. Since strain hardening exponent $n$ is very small in ultrahigh strength steel, the solution of stress distribution in front of a precrack tip in the non-hardening material can be obtained by using the Wall-Hill method; thus

$$
\begin{aligned}
& \sigma_{11}=2 \tau_{0} \ln \left(1+\frac{2 x}{2 V_{c}}\right) \\
& \sigma_{22}=2 \tau_{0}\left[1+\ln \left(1+\frac{2 x}{2 V_{c}}\right)\right] \\
& \sigma_{83}=2 \tau_{0}\left[\frac{1}{2}+\ln \left(1+\frac{2 x}{2 V_{c}}\right)\right]
\end{aligned}
$$

where, $\tau_{0}$ : the shear yield stress

$2 V_{c}:$ the critical crack opening displacement $x$ : the distance from the crack tip.

It is expected to be maximum triaxiality at a distance of $x$ is equal to $1.96\left(2 V_{c}\right)$ from crack tip. We will obtain the following results from Eq. (2);

$$
\begin{aligned}
\sigma_{11} & =2 \tau_{0} \ln 4.92 \\
\sigma_{22} & =2 \tau_{0}(1+\ln 4.92) \quad \ldots \ldots \ldots \ldots \ldots \ldots \ldots \ldots \ldots \ldots \ldots \ldots \ldots \ldots \ldots \ldots \ldots \ldots \ldots \\
\sigma_{33} & =2 \tau_{0}\left(\frac{1}{2}+\ln 4.92\right) \\
\text { so } \quad \bar{\sigma} & =\left\{\frac{1}{2}\left[\left(\sigma_{11}-\sigma_{22}\right)^{2}+\left(\sigma_{22}-\sigma_{33}\right)^{2}+\left(\sigma_{33}-\sigma_{11}\right)^{2}\right]\right\}^{1 / 2} \\
& =\sqrt{3} \tau_{0} \\
\frac{\sigma_{11}+\sigma_{22}}{\bar{\sigma}} & =\frac{2 \tau_{0}[\ln 4.92+(1+\ln 4.92)]}{\bar{\sigma}}=\frac{8.373}{\sqrt{ } 3}
\end{aligned}
$$

Substituting the above results into $\mathrm{Eq}$. (1), we obtained:

$$
\varepsilon_{f}^{*}=0.0345 \ln \frac{\bar{d}_{t}}{\bar{a}}
$$

Furthermore, when the results shown in Tables 2 and 3 are substituted into Eq. (4), a series of $\varepsilon_{f}^{*}$ is obtained as shown in Table 6 .

It shows that $\varepsilon_{f}^{*}$ values are smaller than about 6 times as small as $\varepsilon_{f}$. Why the $\varepsilon_{f}^{*}$ became so smaller than $\varepsilon_{f}$ ? We obtained some data given in Table 7 using the Figs. 10 to 12 taken from the aggregative area of TiN inclusions in specimen No. 6. This method which was used to get the data was that:

The distance between two TiN will be changed from $l_{0}$ to $l_{1}$ when the specimen was loaded, we

\begin{tabular}{|c|c|c|c|c|c|c|c|c|}
\hline \multicolumn{3}{|c|}{ Before necking } & \multicolumn{6}{|c|}{ After necking } \\
\hline$\Delta \varepsilon_{p}$ & $\Delta \varepsilon$ & $\Delta \varepsilon_{p} / \Delta \varepsilon$ & $\Delta \varepsilon_{p}$ & $\Delta \varepsilon$ & $\Delta \varepsilon_{p} / \Delta \varepsilon$ & $\Delta \varepsilon_{p}$ & $\Delta \varepsilon$ & $\Delta \varepsilon_{p} / \Delta \varepsilon$ \\
\hline 3.09 & 2.8 & 1.10 & 7.94 & 2.8 & 2.83 & 10.29 & 2.96 & 3.48 \\
\hline 3.17 & 2.8 & 1.13 & 8.24 & 2.8 & 2.40 & 12.56 & 2.96 & 4.24 \\
\hline 4.13 & 2.8 & 1.47 & 8.95 & 2.8 & 3.20 & 13.59 & 2.96 & 4.59 \\
\hline 5.26 & 2.8 & 1.88 & 9.37 & 2.8 & 3.35 & 15.00 & 2.96 & 5.07 \\
\hline 5.26 & 2.8 & 1.88 & 11.24 & 2.8 & 4.00 & 15.20 & 2.96 & 5.14 \\
\hline
\end{tabular}
get $\varepsilon_{p_{1}}=\left(l_{1}-l_{0}\right) / l_{0}$ and $\varepsilon_{p_{2}}=\left(l_{2}-l_{0}\right)$ so $\Delta \varepsilon_{p}=\varepsilon_{p_{2}}-\varepsilon_{p_{1}}$. There are a lot of TiN in the aggregative area, so we can get a series of $\Delta \varepsilon_{p}$. These data in Table 7 are an evidence that the $\varepsilon_{f}^{*}$ decreases by the inclusions in the aggregative area. Therefore, the specimen containing inclusions breaks easily from aggregative area

Table 6. Calculated and experimental values of fracture strain.

\begin{tabular}{lcccccc}
\hline $\begin{array}{c}\text { Specimen } \\
\text { No. }\end{array}$ & 1 & 2 & 3 & 4 & 5 & 6 \\
\hline $\begin{array}{l}\text { Spacing, } \\
d_{t}(\mu \mathrm{m})\end{array}$ & 87.42 & 74.97 & 64.7 & 55.77 & 53.16 & 50.86 \\
$\begin{array}{l}\text { TiN size, } \\
\bar{a}(\mu \mathrm{m})\end{array}$ & 1.7 & 1.7 & 2.1 & 1.9 & 2.0 & 2.2 \\
$\begin{array}{l}\text { Fracture } \\
\text { strain, } \varepsilon_{f}\end{array}$ & 0.76 & 0.75 & 0.70 & 0.73 & 0.67 & 0.63 \\
$\begin{array}{l}\text { Calculat- } \\
\text { ed strain, } \\
\varepsilon_{f}\end{array}$ & 0.136 & 0.131 & 0.118 & 0.116 & 0.113 & 0.108 \\
\hline
\end{tabular}

Table 7. Ratio of localized strain increment, $\Delta \varepsilon_{p}$, and macro strain increment, $\Delta \varepsilon$, in the aggregative area. (\%) 


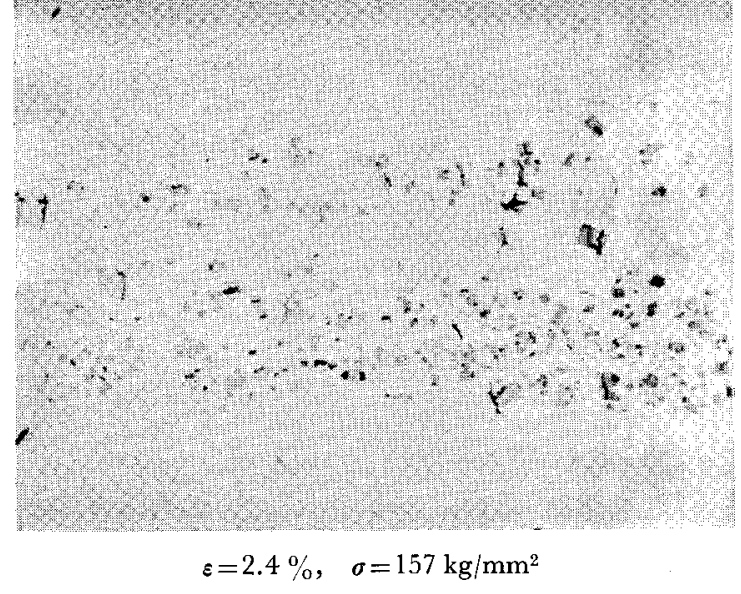

Fig. 10. TiN inclusions and microcrack growth. $(\times 500)(\times 7 / 10)$

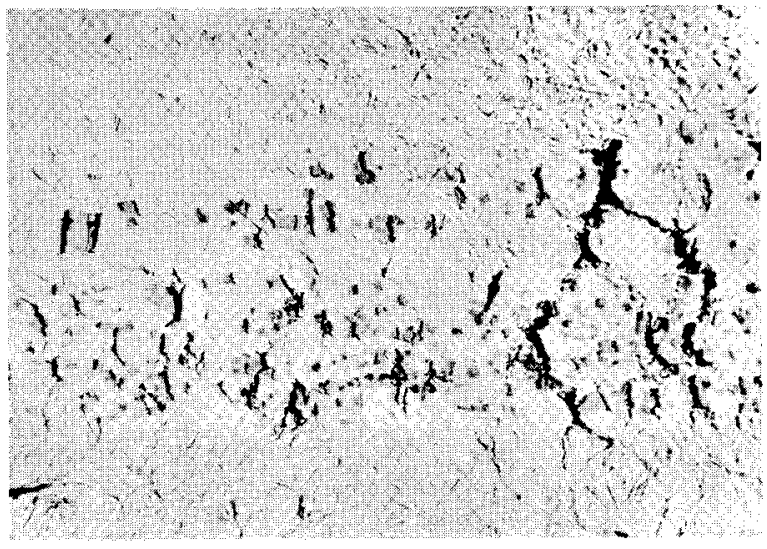

$\varepsilon=5.2 \%, \quad \sigma=178 \mathrm{~kg} / \mathrm{mm}^{2}$

Fig. 11. TiN inclusion and microcrack's propagation. $(\times 500)(\times 7 / 10)$

of inclusions.

\subsection{Relations of Crack Propagation to Inclusions Spacing and Fracture Toughness}

The crack propagation may be controlled by $\varepsilon_{f}^{*}$ deduced from Eq. (4). It has been known that the $\varepsilon_{f}^{*}$ is proportional to $\bar{d}_{T}$. Therefore, the crack propagation may be also controlled by $\bar{d}_{T}$. Through the observation of plane tensile specimen (No.6), we found that the microcracks in TiN inclusion were linkaged in the aggregative area of TiN inclusion (Fig. 12) resulting in lower fracture toughness for specimen No. 6.

The effect of the inclusion spacing $\left(\bar{d}_{T}\right)$, which is determined by metallographs is shown in Fig. 13. There is a good linear relationship between $K_{\text {IC }}$ and $d_{T}^{1 / 2}$. Its linear dependence coefficients is:

$$
r_{m}=0.9945
$$

We get a linear equation by regression analysis as follows:

$$
K_{\text {IC }}=K(d t)^{1 / 2}
$$

Another dructile fracture model had been proposed by Rice, ${ }^{11)}$ i.e. :

$$
\kappa_{\mathrm{IC}}=\left(2 E \sigma_{y} d_{T}\right)^{1 / 2}
$$

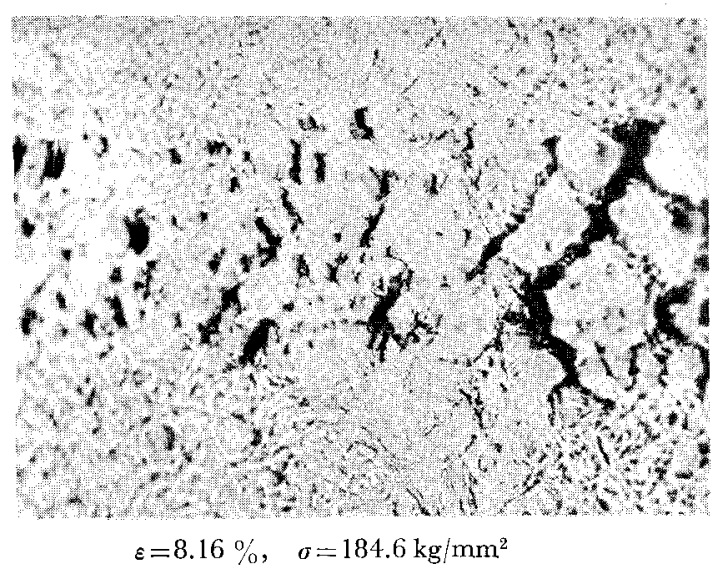

Fig. 12. TiN inclusion and microcrack's propagation. $(\times 500)(\times 7 / 10)$

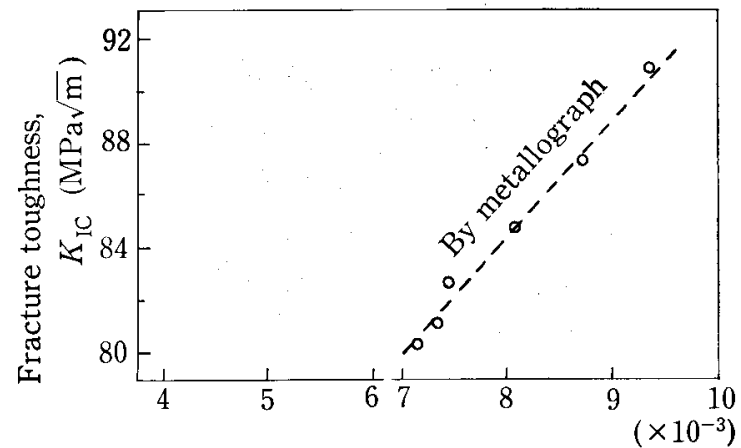

Square root of inclusion spacing $\left(\mathrm{m}^{1 / 2}\right)$

Fig. 13. Relation between $K_{\mathrm{IC}}$ and $d_{t}^{1 / 2}$.

Table 8. A comparison between $K_{\text {IC }}$ values. $\left(\mathrm{MPam}^{1 / 2}\right)$

\begin{tabular}{lcccccc}
\hline \multirow{2}{*}{$K_{\mathrm{IC}}$} & \multicolumn{6}{c}{ Specimen No. } \\
\cline { 2 - 7 } & 1 & 2 & 3 & 4 & 5 & 6 \\
\hline $\begin{array}{l}\text { By testing } \\
\text { Calculated }\end{array}$ & 90.9 & 87.3 & 84.9 & 82.7 & 81.1 & 80.4 \\
$\begin{array}{l}\text { by } K_{\mathrm{IC}}= \\
\left(2 E_{\sigma_{y}} \bar{d}_{r}\right)^{1 / 2}\end{array}$ & 142.1 & 132.6 & 117.0 & 116.5 & 113.3 & 108.5 \\
$\begin{array}{l}\text { Calculated } \\
\text { by } K_{\mathrm{IC}}= \\
\left(E_{\sigma_{y}} \bar{d}_{r}\right)^{1 / 2}\end{array}$ & 100.6 & 93.7 & 82.7 & 82.5 & 80.1 & 76.7 \\
\hline
\end{tabular}

where, $\sigma_{y}, E$ : constants for known material.

When comparing the two $K_{\mathrm{IC}}$ values calculated from Eqs. (5) and (6) with the measured values, we get useful results given in Table 8 .

When the constant $K$ in Eq. (5) is equal to $\left(E \sigma_{y}\right)^{1 / 2}$, the calculated $K_{\mathrm{IC}}$ values is closer to the measured $K_{\text {IC }}$ values than $K_{\text {IC }}$ values calculated from $k=\left(2 E \sigma_{y}\right)^{1 / 2}$ (the Rice Model). Therefore, we propose that the relation of $K_{\mathrm{IC}}$ to $\bar{d}_{T}$ is expressed as follows:

$$
K_{\mathrm{IC}}=\left(E \sigma_{y} d_{T}\right)^{1 / 2}
$$

In comparison with the effects of size and number of inclusion of the fracture toughness, in the range of inclusion size of $0 \sim 0.55 \mu \mathrm{m}$, the inclusion number of specimen No. 2 is larger than that of specimen No. 6, but $K_{\text {IC }}$ value of No. 2 is higher than that of No. 6 (Table 3). On the other hand, in the range of inclusion size above $5.7 \mu \mathrm{m}$ the number of inclusions in No. 6 is larger than that in No. 2. Therefore, it was 
confirmed that the effect of inclusion size is more harmful than number of inclusions on fracture toughness.

\section{Conclusion}

The fracture toughness appears to be markedly effected by TiN inclusion content and spacing. The most effective measures for improve the toughness of steel are to reduce the nitrogen contents and aggregation of inclusion, or to refine the inclusion particles.

\section{Acknowledgement}

The authors wish to thank their colleagues at the Institute of Metal Research of Academia Sinica for helpful in the work on 1984 1985 when the authors worked in there.

\section{REFERENCES}

1) D. Brooksbank and K. W. Andrews: J. Iron Steel Inst., 206 (1968), 595; 207 (1969), 474.
2) A.J. Birkle, R.P. Wei and G. E. Pellissier: Trans. Am. Soc. Met., 59 (1966), 981

3) W. A. Spitzig: Trans. Am. Soc. Met., 61 (1968), 344.

4) V.P. Raghupathy and R. Vasuclevan: Materialpruf, 24 (1982), No. 7, 243

5) K. Eriksson: Scand. J. Metall., 4 (1975), 131.

6) A. S. Argon, J. Im and R. Safaglu: Metall. Trans. A, 6A (1975), 825.

7) A. Sides: Eng. Frac. Mechanics, 20 (1984), No. 1, 83.

8) S. H. Goods and L. M. Brown: Acta metall., 27 (1979), 1.

9) K. Tanaka, T. Mori and T. Nalamura: Phil. Mag., 21 (1970), 267.

10) F. A. McGlintock: Trans. ASME, J. Appl. Mech., 35 (1968), 362.

11) J. R. Rice and D. M. Tracey: J. Mech. Phys. Solids, 17 (1969), 201.

12) R. D. Thomson and J. W. Hancook: Int. J. Fract., 26 (1984), 99 .

13) G. T. Hahn and A. R. Rosenfield: Applications Related Phenomena in Titanium Alloys, ASTM Spec. Tech. Pub. No. 432, (1968), 5-32.

14) D. E. Osborne and Embury: Metall. Trans., 4 (1973), 2051. 